\title{
The Pedagogical Conditions for Reflexive Culture Improvement of Future Teachers
}

\author{
Belegova Aliya, M. Bulakbayeva, E. Barangulov, A. Kenjan, S. Koshimbetova and \\ Tussupbekova Gulmira
}

\author{
Kazakh National Pedagogical University named after Abai, Almaty, Kazakhstan
}

\begin{abstract}
Changes in the socio-political and economic guidelines of modern society have led to the advancement of new requirements for a university graduate to his preparedness level. A market economy with the fierce competition requires specialists who are sensitive to creative work, highly professional, mobile, capable of finding and implementing new, effective forms of organizing their activities.
\end{abstract}

The research problem is to search for pedagogical conditions that ensure the formation of professional-pedagogical reflection in future teachers in the process of studying at a university.

The purpose of the research is to identify the level of developed skills in reflexive culture and experimentally prove the pedagogical conditions for the formation of professional-pedagogical reflection of the students of the educational faculties and enhance future teacher reflexive culture, especially of the teacher of physical training.

Drawing on educational practices at the Abai Kazakh National Pedagogical University (KAZNPU) further, this paper presents the results of the future teacher reflexive culture $(R C)$ enhancement process. It presents various content-based approach models-including those that have been developed at the KAZNPU and, examines the decision-making process of future teacher reflexive culture enhancement for a particular educational setting.

This research comes to the conclusion that during the development of future teachers' reflexive culture, it is necessary to use the set of methodological tools supporting the educational process.

Keywords: Pedagogical conditions, future, teacher, reflexive, culture, enhancement.

\section{INTRODUCTION}

Under the conditions of constant renewal and restructuring of all spheres of human activity, the view on the educational system changes. The change of conceptual and value bases of professionalpedagogical activity leads to the emergence of sharp contradictions between the teacher's current state as a professional and the ever-increasing requirements for him and the qualitative characteristics of his work.

Paying some attention to the reflective training of students and the reflective management of them in the process of studying at a university, researchers pay great attention to the study of the role and place of professional reflection of the teacher, understanding it as a specific form of theoretical activity, as a kind of procedure for summing up the results of educational and educational activities. Simultaneously, forming professional-pedagogical reflection is considered a process of developing reflexive abilities, properties of a future teacher, the formation of his qualities, readiness, a set of reflexive knowledge, and skills. However, it is known that reflection is also associated with emotional reactions, with cognitive representations, and with the

*Address correspondence to this author at the Kazakh State National University of Al-Farabi, Almaty, Kazakhstan; Tel: +77073851878;

E-mail: zhanat_2006@mail.ru teacher's position in general, but this aspect is not sufficiently represented in the available research.

Therefore, we understand professional-pedagogical reflection as an active research position of a teacher in relation to his activity and himself as to its subject with the aim of the constructive transformation of professional activity and further self-improvement.

The problem of reflection was one of the basic conditions of personality formation from the earliest times of human development, and it has been the focus of philosophers, psychologists, teachers, and scientists of various branches of knowledge. This study aims to theorize or establish reflexivity as a learning method. The future teacher needs to connect diverse thoughts about reflexivity and attempt to understand effective practices to cultivate a space of reflection for students and devise effective ways and methodologies to foster reflexive thought among student learners.

\section{Problem Statement}

A future teacher's reflexive culture is formed in the presence of a few related factors, internal and external, that positively or negatively affect the process of its formation. These factors exist as problems faced in configuring a future teacher's reflexive culture. The first of these concerns is that the formation of a teacher's 
reflexive culture cannot be carried out in isolation or by segregating the teacher away from his or her other professional activities. The difficulties of professionalism require the reflection of a special type of analysis or identifying theoretical and practical aspects prior to building a future teacher's reflective culture. Critics have opined that reflexive culture is "dialectically" connected with the content and specificity of a teacher's professional activity. Hence, it is important to investigate the role of professionalism in forming the future teacher's reflective culture.

Secondly, the formation of a reflexive culture is a time-consuming, long-term process that depends on many factors. Suppose a teacher is self-improving, self-governing, and reflective. In that case, the process starts with forming a reflexive culture while interacting with students from the first days at the University. $X Y Z$ has recommended that preparation for a reflexive culture could be a psychological and pedagogical process [1].

This study aims at addressing a few of these issues by first talking about the theoretical and practical aspects of the formation of a teacher's reflective culture. It aims to formulate rules and norms that could build up a reflexive culture and create a system of requirements that predetermine the processes of developing such norms and regulations. The urgency of the problem, its social significance, insufficient theoretical and practical development, determined the research topic "Formation of future teacher reflexive culture". Theoretically substantiate and experimentally test the methodology of the formation of the teacher's reflective culture. And the reflexive culture itself is understood by us as a system of requirements that predetermine the processes of developing norms of reflection created with the involvement of intellectual and value criteria.

\section{LITERATURE REVIEW}

Dewey and Schön have promulgated the theoretical and practical aspects of the notion of reflection [2]. Dewey defined the reflexive practice as an action that involves "active, persistent, and careful consideration of any belief or supposed form of knowledge in light of the grounds that support it and the further consequences to which it leads". Schön made the distinction between reflection "in action"- kind of reflection that occurs whilst a problem is being addressed, and "on action"- that takes place after the event, it's consciously undertaken and documented. In either case, the process of development of a reflexive culture is initiated for an in-service teacher. It promises to enhance teachers' capacity of self-observation, selfanalysis, and self-evaluation [3].

Flores see reflexivity arising from students' images of teachers, their initial beliefs, and concepts of what represents a good teacher. Through the processes of reflection, such teachers' identity is refined to develop a higher understanding of teachers, through educational experiences [4].

Several writings have investigated the issue of reflexivity. For instance, Bauman was counter-intuitive to reflexivity and asserted that reflexivity was predominantly dependent on a limited potential collaboration of individual teachers. Bauman posed a challenge to future teachers that need to be addressed while adding reflexivity to a course [5]. A similar study was carried out by Lefoe, who contended that the constructivist learning theory could establish an environment of reflexive culture for future teachers. The study drew numerous connections between reflexivity and constructivist learning and provided a thorough overview of the theory, its implications, and its applications [6]. Matthew and Jessel distinguish between reflection and reflexivity, explaining reflexivity is being self-aware within certain moments and situations and leads to a better understanding of those situations through a better understanding of ourselves [7]. Their study found that teachers who observed reflexivity were more apt to be involved in reflexive learning [8]. Macfarlane challenged the role of reflection within a learning environment and emphasized to remain aware of concerns with reflexivity in order to understand better the process and how to use it [9].

Mezirow posed methods and guidelines for teachers to create effective learning experiences, hoping to bring about self-directed motivation from the learners. This motivation would easily fit within an online learning community. Reflexivity is one way he suggests bringing about Andragogy, which he defines as "an organized and sustained effort to assist adults in learning in a way that enhances their capability to function as selfdirected learners." More recently, Paily recommended creating a constructivist learning environment within an online learning space and emphasized to deal with the technological approaches and methodologies that might be utilized within this environment [10].

Similarly, Tanaka creates Intercultural theory using an amalgamation of other educational and social 
theories in order to craft a new framework for higher education. He points to the genealogy of reflexive practices and the postmodern turns of social theories. He explores students' cultural backgrounds to better their experiences in the classroom [11].

\section{RESEARCH OBJECTIVES}

The major objectives of this study were:

1. To identify the main aspects of the formation of a teacher's reflective culture.

2. To explore whether there exist any rules and norms to build a reflexive culture.

\section{Research Questions}

1. What are the main aspects of the formation of a teacher's reflective culture?

2. Are there any rules and norms required to build a reflexive culture?

\section{Research Methods}

A survey questionnaire was used to collect data for the study. The subjects were administered a questionnaire in which they were asked to answer questions related to their reflexive culture and actions. The questionnaire was framed based on the related literature and a few preliminary interviews conducted with some future teachers. Descriptive and inferential analyses were conducted to get a deeper insight into the research questions. The time limit was 90 minutes for the survey.

As a result of the diagnosis, two indicators were obtained - self-reflection and social reflection, ranging from 10 to 60 points. The ratio of the two forms of reflection was analyzed. The most "adapted" was considered to be the average level of self- reflection and a high or above-average level of social reflection. Experimental groups with fundamentally different initial parameters were formed. These groups included subjects with different reflexive culture levels, work experience, nature, and content of activities. In all groups, external and internal factors of reflexive culture formation were more or less favorable for the experiment.

The questionnaire consisted of 1 scale - selfreflection. The scale included 10 direct and inverse statements, each of which, in turn, was evaluated on a 6-point scale: 1 - absolutely disagree, 2 - disagree, 3 rather disagree, 4 - rather agree, 5 - agree, 6 absolutely agree.

\section{Table 1: Items Used for Self-Reflection Questionnaire}

\begin{tabular}{|l|}
\hline 1. I tend to analyze my feelings. \\
\hline $2^{*}$ I rarely think about the reasons for my behavior. \\
\hline $3^{*}$. As a rule, I just act on the situation, without hesitation. \\
\hline 4. It is important for me to understand how my thought works. \\
\hline 5. I often wonder why I act one way or another. \\
\hline 6. I usually listen to my inner feelings. \\
\hline 7. I always appreciate my feelings and actions. \\
\hline 8. When I work, I carefully control my actions. \\
\hline 9. By nature, I am a person inclined to introspection. \\
\hline 10. I love to spend time alone with myself. \\
\hline
\end{tabular}

Based on the analysis, we constructed a theoretical model of reflexive culture formation, which is a system that includes three components.

Components of readiness of the future teachers to work with students of deviant behavior

\begin{tabular}{|c|l|l|}
\hline Components & \multicolumn{1}{|c|}{ Criteria } & \multicolumn{1}{|c|}{ Indicators } \\
\hline \hline Motivational aimed & $\begin{array}{l}\text { - motivation, responsibility for future sporting and } \\
\text { healthy lifestyles; } \\
\text { - formation of universal human and social-personal } \\
\text { values; } \\
\text { - Providing psychological and pedagogical and } \\
\text { specialized basic education as the foundation of } \\
\text { vocational education. }\end{array}$ & $\begin{array}{l}\text { - formation of reflexive culture in accordance with the laws, } \\
\text { regularities, principles, educational mechanisms of the } \\
\text { pedagogical process; } \\
\text { - the formation of reflexive culture, which is based on the } \\
\text { intellectual abilities of future physical education } \\
\text { professionals, what knowledge and skills they can handle, } \\
\text { the heuristic approach to the needs and the needs of } \\
\text { society. }\end{array}$ \\
\hline Processual content & $\begin{array}{l}\text { - Implement the content of the process of reflexive } \\
\text { culture formation; } \\
\text { - correction of the interaction of sports-healthcare } \\
\text { process participants in forming a reflexive culture of } \\
\text { physical fitness professionals. }\end{array}$ & $\begin{array}{l}\text { - Understanding the goals, objectives, and stages of what } \\
\text { actions and what experimental work to create a program } \\
\text { for the formation of the reflection culture of future physical } \\
\text { education professionals; } \\
\text { - Understanding the essence of the scientific and } \\
\text { theoretical material depending on the content of the } \\
\text { process of reflexive media formation, presence in scientific } \\
\text { research. }\end{array}$ \\
\hline
\end{tabular}




\begin{tabular}{l|l} 
Reflexive & $\begin{array}{l}\text { - development of professionalism of future physical } \\
\text { assessing }\end{array}$ \\
& $\begin{array}{l}\text { training specialists; } \\
\text { - Efficient use and improvement of knowledge of } \\
\text { innecialists. }\end{array}$
\end{tabular}

- Diagnosis and analysis of the results of the process of formation of reflexive culture, results for the purpose and correction;

- Comparison with the effectiveness of the model of reflexive culture formation

\section{RESULTS AND DISCUSSIONS}

Based on the characteristics of the components, criteria, and indicators of reflexive culture formation required, we also identified the following potential levels of its formation for future teachers: high, sufficient, medium, low. A certain volume of features available to future teachers characterizes each level

State of reflexive culture formation of the future teachers

\begin{tabular}{|c|c|c|c|c|c|c|c|c|c|c|c|c|c|c|c|c|}
\hline \multirow[t]{3}{*}{$\mathbf{N}$} & \multirow[t]{3}{*}{ Level of RC } & \multicolumn{15}{|c|}{ Criteria and features } \\
\hline & & \multicolumn{4}{|c|}{$\mathbf{I}$} & \multicolumn{4}{|c|}{ II } & \multicolumn{4}{|c|}{ IIII } & \multicolumn{3}{|c|}{ IV } \\
\hline & & 1 & 2 & 3 & 4 & 5 & 6 & 7 & 8 & 9 & 10 & 11 & 12 & 13 & 14 & 15 \\
\hline 1 & High & + & + & + & + & + & + & + & + & + & + & + & + & + & + & + \\
\hline 2 & Sufficient & + & + & + & + & + & + & + & + & + & + & + & + & - & - & - \\
\hline 3 & Average & + & + & + & + & + & + & + & + & + & - & - & - & - & - & - \\
\hline 4 & Low & + & + & - & - & - & - & - & - & - & - & - & - & - & - & - \\
\hline
\end{tabular}

Identified criteria for evaluating each of these components of the RC formation of the future teachers were the basis of differentiation of each component on the level of formation. In accordance with these levels of students who have completed 2 nd year are distributed in the control and experimental groups of 4 levels (1-high, 2-sufficient, 3-average, 4-low). Summarizing the quantitative results obtained in all components of RC of the future teachers, we have the following characterization of each appeared component in the study.

Distribution of students by level of development of components of RC of the future teachers (summarized data in $\%$ at the beginning of ODA)

As can be seen from Table, we have presented here is not only the distribution of students by level of development components of RC study, but also presented mean values of formation of $\mathrm{RC}$ levels for each component, which in the future will allow us to compare the original data with the results obtained above.

Having calculated the mean values of each level of reflexive culture, the average value was calculated over an interval. The formula for the average value of a function, $f$, over the interval from $a$ to $b$ is: average $=\frac{1}{b-a} \int_{a}^{b} f(x) d x$

where

$x$ is the number of levels achieved, $b-a$ is the time interval

In such a situation, there might be an indefinite number of levels to achieve. Suppose we take the number of levels as infinity; in that case, it is difficult to get the average value and difficult to obtain values of low and average levels of reflexive components of a teacher's reflexive culture.

To achieve this goal in the study were identified and theoretically justified the formation of a reflexive culture of the future teacher in the learning system: pedagogical diagnosis of the level of formation of a reflexive culture of the future teacher; the implementation of didactic cycles (cognitive, technological, personal) in the learning process; acmeological support of personal and professional growth of the teacher. Based on the selected criteria (motivational aimed, processual content, reflexive assessing) and indicators, the levels (high, sufficient, average, low) of the formation of the teacher's reflexive culture are determined and characterized. 


\begin{tabular}{|c|c|c|c|c|c|c|c|c|c|c|c|}
\hline \multirow[t]{2}{*}{$\mathbf{N}$} & \multirow[t]{2}{*}{ Components } & \multicolumn{5}{|c|}{ Control group } & \multicolumn{5}{|c|}{ The experimental group } \\
\hline & & 1 & 2 & 3 & 4 & $\begin{array}{c}\text { The } \\
\text { average } \\
\text { value }\end{array}$ & 1 & 2 & 3 & 4 & $\begin{array}{c}\text { The } \\
\text { average } \\
\text { value }\end{array}$ \\
\hline 1 & $\begin{array}{l}\text { Motivational } \\
\text { aimed }\end{array}$ & 44 & 33,9 & 13,7 & 4,4 & 2,85 & 46,5 & 37,5 & 12,7 & 3,4 & 2,88 \\
\hline 2 & $\begin{array}{c}\text { Processual } \\
\text { content }\end{array}$ & 9,3 & 17,1 & 43,7 & 30,8 & 2,68 & 7,5 & 19,8 & 42,9 & 30,2 & 2,78 \\
\hline 3 & $\begin{array}{l}\text { Reflexive } \\
\text { assessing }\end{array}$ & 4,8 & 8,9 & 37,8 & 50,4 & 2,26 & 4,5 & 9,2 & 34,7 & 51,4 & 2,28 \\
\hline
\end{tabular}

The complex of four didactic cycles (motivational aimed, processual content, reflexive assessing) providing transitions from one level of formation of reflexive culture to another, higher is developed for the efficiency of forming a reflexive culture of teachers in the system of professional development. Implementation of didactic cycles and acmeological support allowed solving the problem of personal and professional growth in the process of the formation of reflexive culture in the learning system. The final diagnosis of the results of the formative stage of the experiment proved the effectiveness of the proposed model of the formation of future teacher RC.

To ensure an effective process of forming a reflexive culture requires a complex combination of traditional lecture and seminar classes, as well as new active (discussion forms, simulation games, training) forms and methods of training. Simultaneously, the latter is of priority importance, since the reflexive culture cannot be translated, only "grown". The cyclical nature of the process of formation of reflexive culture is determined by the need to accumulate knowledge and operational (technological) base for solving increasingly complex problems of improvement and development of activities, their own professionalism, and personal qualities. The process of formation of reflexive culture is carried out mainly in the dialogue interaction, organized by the type of complex communication, modeling of procedures of reflexive and mental processes.

By the degree of teacher reflexive culture increasing, the educational process becomes more individual, focused on achieving the heights in a particular person's professional and individual life. Only at a sufficient level reflexive culture is formed, and in our study, we relate the problem to this level, the teacher becomes capable of metareflexia (analysis and evaluation of real reflective actions and thought processes associated with them), which leads to the formation of creativity and self-awareness of a future teacher as an innovator [12].

The teaching approaches are a mixture of problemsolving and practical workshops that incorporate teamwork, collaborative learning, and whole class input and discussion. This offers learners a flexible approach to learning with a special emphasis on peer teaching, which is important given the range of abilities [13].

On balance, the functions observed in the current study are consistent with the findings of earlier studies in the literature on learners' skills development about learning. In this study, Kazakhstan university students have strong beliefs about learning and especially the formation of a teacher's reflexive culture. [14]

\section{CONCLUSION}

The concept of professional-pedagogical reflection has been concretized as an active research position of a teacher in relation to his activity and himself as to its subject with the aim of the constructive transformation of professional activity and further self-improvement.

The essence of professional-pedagogical reflection is revealed during the pedagogical process of a teacher, which means the knowing himself as a professional, understanding of his inner world, and analyzing his own professional and personal knowledge, together with the behavior and experiences in connection with the professional-pedagogical activity.

Revealed the content of professional-pedagogical reflection from the point of view of the positional approach, which is presented as a unity of three spheres: cognition, action, and experience.

The essence and content of the teacher's professional reflection from the point of view of the positional approach represents the priority of the 
formation of internal, personal sources, which is considered the basis of the motivational-value attitude to the teaching profession.

The results of experimental work showed that the set of pedagogical conditions which we used during the experiment helps students to develop the reflexive culture and aims students with reflexive knowledge and skills. Also the set of methods which we used during research work helps students to raise their professionalism in their work.

\section{REFERENCES}

[1] Andreyev AA. The problem of learning objectives in modern pedagogy Chicago 2009.

[2] Dewey J. How we think: A restatement of the relation of reflective thinking to the educative process. Chicago: Henry Regnery 1933.

[3] Schön D. The reflective practitioner. New York: Basic Book 1983.

[4] Flores MA, Day C. Contexts which shape and reshape new teachers' identities: a multi-perspective study. Teaching and Teacher Education 2006; 22(2): 219-232.

[5] Bauman E. Emotions and reflexivity in feminised education action research. Educational Action Research 2006; 14(3): 315-332.
[6] Lefoe G. Creating Constructivist Learning Environments on the Web: The Challenge in Higher Education. ASCILITE 1998; 98: 453-464.

[7] Geijsel F, Meijers F. Identity learning: the core process of educational change. Educational Studies 2005; 31(4): 419430. Gouldner AW. The coming crisis in Western sociology. New York: Basic Books 1970.

[8] Macfarlane B, Lesley G. The Reflection Game: Enacting the Penitent Self. Teaching in Higher Education 2009; 14(4): 455-459.

[9] Matthew B, John J. Reflective and Reflexive Practice in Initial Teacher Education: A Crucial Case Study. Teaching in Higher Education 1998; 3(2): 23.

[10] Mezirow J. How critical reflection triggers transformative learning. In Mezirow J, (Eds.), Fostering critical reflection in adulthood: A guide to transformative and emancipatory learning. San Francisco: Jossey-Bass 1990.

[11] Tanaka GK. Higher Education's Self-Reflexive Turn: Toward an Intercultural Theory of Student Development. The Journal of Higher Education 2002; 73(2): 263-296. Print

[12] Ibragimova T, et al. Enhancement of Creativity in Math Skills of People with ID in Education Process. J Intell Disabil Diag Treat 2019; 7(4) 260-264.

[13] Gulnar $O$, et al. The Foreign Language Students' Beliefs Regarding Learning Strategies In Different Kazakhstan University Students. J Intell Disabil Diag Treat 2018; 6(3): 96104.

[14] Bermus AG. Philosophy of education and education policy. M., 2003; p. 100.

Received on 05-08-2020

Accepted on 30-08-2020

Published on 14-09-2020

DOI: https://doi.org/10.6000/2292-2598.2020.08.03.36

(C) 2020 Aliya et al.; Licensee Lifescience Global.

This is an open access article licensed under the terms of the Creative Commons Attribution Non-Commercial License (http://creativecommons.org/licenses/by-nc/3.0/) which permits unrestricted, non-commercial use, distribution and reproduction in any medium, provided the work is properly cited. 